\title{
A genetically homogenous population of Fusarium circinatum causes pitch canker of Pinus radiata in the Basque Country, Spain
}

\author{
Eugenia Iturritxa ${ }^{1}$, Rebecca J. Ganley ${ }^{2}$, Jane Wright ${ }^{3}$, Endika Heppe ${ }^{1}$, Emma T. Steenkamp ${ }^{3}$, \\ Thomas R. Gordon ${ }^{4}$ and Michael J. Wingfield ${ }^{5}$
}

(1) Neiker, Granja Modelo de Arkaute, PO Box 46, E-01080 Vitoria-Gasteiz, Spain.

(2) Scion, New Zealand Forest Research Limited, Private Bag 3020, Rotorua, New Zealand.

(3) Department of Microbiology and Plant Pathology, Forestry and Agricultural Biotechnology Institute (FABI), University of Pretoria, Pretoria 0002, South Africa.

(4) Department of Plant Pathology, University of California, Davis, CA 95616, USA.

(5) Forestry and Agricultural Biotechnology Institute, University of Pretoria, Pretoria 0002, South Africa.

Rebecca J. Ganley

Email: rebecca.ganley@scionresearch.com

\begin{abstract}
Pitch canker, caused by Fusarium circinatum, is a destructive disease of Pinus species and has recently been shown to represent a substantial threat to natural and commercial forests in northern Spain. The genetic diversity of F. circinatum in the Basque Country of Spain was assessed by characterising 96 isolates based on vegetative compatibility groups (VCGs), mating type assays, polymorphic DNA-markers and amplified fragment length polymorphism (AFLP) analyses. For this purpose, F. circinatum isolates were collected from diseased Pinus radiata as well as from insects associated with this host. Overall, a low level of diversity was detected in the population. The isolates represented only two VCGs and they were all of the same mating type. AFLP analyses revealed three genotypes and polymorphic DNA-markers specific for F. circinatum showed nine genotypes. The most common genotypes represented $97 \%$ of all isolates for AFLP analysis and 68 $\%$ of isolates for the polymorphic DNA-marker sets. Over all, this indicates that pitch canker in the Basque Country of Spain is caused by a clonally propagating population of $F$. circinatum, typical of a recently introduced pathogen.
\end{abstract}

\section{Introduction}

Pitch canker, caused by Fusarium circinatum (Nirenberg \& O'Donnell 1998) (teleomorph = Gibberella circinata), is a destructive disease of Pinus species. The disease is characterised by heavy exudation of resin at the site of infection (Wingfield et al. 2008). In addition to negatively impacting growth, this pathogen is capable of killing both mature trees and seedlings.

The first report of pitch canker was in North Carolina, USA in the 1940s (Hepting \& Roth 1946) and the pathogen is now known to be present across the southeastern United States, as well as in California (Dwinell et al. 1985; McCain et al. 1987; Wingfield et al. 2008). The disease has also been recorded in numerous countries worldwide, including Haiti (Hepting \& Roth 1953), Chile (Wingfield et al. 2002), South Africa (Viljoen et al. 1994), Japan (Kobayashi \& Muramoto 1989), Korea (Lee et al. 2000), Mexico (Britz et al. 2001), Italy (Carlucci et al. 2007), Portugal (Braganca 
et al. 2009) and Spain (Landeras et al. 2005). Fusarium circinatum has been found to be pathogenic to, or reported on, over 60 species of pine (Hodge \& Dvorak 2000; Gordon 2006), and one non-pine host, Pseudotsuga menziesii (Douglas-fir) (Storer et al. 1997). Of these, Pinus radiata is considered to be one of the most susceptible (Gordon et al. 2001). This pathogen represents a significant threat to regions where Pinus species or P. menziesii occur naturally or where native or non-native species are commercially grown.

Successful pitch canker infections require wounds or openings on the tree as intact tissue is not vulnerable to invasion by the fungus (Gordon et al. 1998a). In general, pitch canker is associated with wounds created by insects, weather or mechanical damage, and spores can be disseminated by wind, rain, animals, insects or soil. The importance and association of vectors and wounding agents can vary between locations where pitch canker occurs. For instance, in the southeastern United States, infection courts are thought to be created primarily by weather and mechanical damage (Dwinell et al. 1985), whereas in California pitch canker infections are associated mainly with wounding caused by insects (Gordon et al. 2001). The pathogen can also be transmitted via seed. Infected seed often display no symptoms until the seed germinates, although in some cases infected seed can germinate and produce symptomless seedlings from which the fungus can be isolated (Storer et al. 1998).

Fusarium circinatum, which is thought to spread primarily by conidia produced as a result of asexual reproduction, is a heterothallic fungus in which sexual compatibility is determined by a single mating type locus harbouring one of two alternative idiomorphs: MAT-1 or MAT-2 (Kerenyi et al. 1999). The sexual stage ( $G$. circinata) has not been observed in nature but has been produced under controlled conditions (Britz et al. 2002a; Viljoen et al. 1997a). Numerous studies have sought to assess the relative importance of sexual and asexual reproduction in natural populations of $F$. circinatum by characterising vegetative compatibility group (VCG) diversity, determining the relative frequencies of the two mating type idiomorphs or using DNA based polymorphic markers to assess genotypic diversity (Britz et al. 2005). Based on these studies, it appears that clonal propagation dominates in most populations, but recent outcrossing cannot be excluded in all cases (Correll et al. 1992; Gordon et al. 1996; Viljoen et al. 1997b; Wikler \& Gordon 2000).

In the northern regions of Spain, pitch canker poses a serious threat to commercial plantations of non-native $P$. radiata and $P$. menziesii as well as native populations of Pinus pinaster and Pinus sylvestris (Landeras et al. 2005). Perez-Sierra et al. (2007) sampled populations of $F$. circinatum from $P$. radiata, Pinus nigra, $P$. pinaster and $P$. sylvestris in three adjacent, autonomous communities (Galicia, Asturias and Cantabria) on the north coast of Spain, where they found both mating types of the fungus to be present. This implies that the pathogen has the capacity for sexual reproduction, although additional evidence is required to demonstrate that out-crossing actually occurs in these populations.

In the Basque Country of Spain, $P$. radiata is considered to be the most important plantation species. This species accounts for almost $60 \%$ of the forested area in Bizkaia, a province within the Basque Country (Gonzalez-Ariasa et al. 2006). The presence of pitch canker in the Basque Country and its association with bark beetles is a serious concern to its forest industry (Romon et al. 2007). The objective of this study was to characterise the genetic diversity of $F$. circinatum in the Basque Country using mating type assays, VCG tests, DNA-based polymorphic markers, and amplified fragment length polymorphism (AFLP) analyses. This information is expected to provide insights into the predominant mode of reproduction in this population and how recently it may have become established in the Basque Country. 


\section{Materials and methods}

\section{Collection and isolation of Fusarium circinatum}

In 2004, two sets of collections of Fusarium circinatum were obtained from Pinus radiata displaying symptoms resembling those of pitch canker (i.e., stems exuding resin, flagged branches with apparent cankers) in the Basque Country of Spain. The first set of collections (Collection 1) consisted of isolates collected from $P$. radiata across the provinces of Bizkaia, Gipuzkoa and the northern region of Araba. One individual stemor branch canker was sampled fromeach tree. The second set of collections of isolates (Collection 2) was obtained from three $P$. radiata plantations in Durango (P1) and Laukiz (P2) in the province of Bizkaia, and Onyi (P3) in the province of Gipuzkoa, which subsequently have been destroyed. For each plantation, the sampling strategy involved collecting one individual stem or branch canker from each of 20 symptomatic trees and 10 samples (individual stem or branch cankers) from a single, heavily infected, symptomatic tree. Any insects found in association with the trees sampled in plantation P3 were also collected. This included insects found on the bark of the trees or insects found inside the tree where cankers were sampled.

To isolate the pitch canker fungus, stem or branch canker samples were surface sterilised with $1 \%$ sodium hypochlorite and plated onto Fusarium selective medium(FSM), as described by Aegerter \& Gordon (2006), and $4 \%$ (w/v) potato dextrose agar (PDA), while insects were plated directly onto FSM. Plates were sealed with parafilm and incubated at $22 \mathrm{C}$ in the dark. Any resulting fungal colonies resembling $F$. circinatum in culture were isolated by transferring a germinated single conidium to fresh PDA medium. All of the subsequent single-conidium isolates (CMW28934CMW29025, CMW32945-CMW32948) used in this study are maintained in the culture collection of the Forestry and Agricultural Biotechnology Institute (FABI),University of Pretoria, South Africa. A representative strain (CECT 20759) has been deposited in the Spanish Type Culture Collection, Coleccion Espanola de Cultivos Tipo (CECT), at the University of Valencia, Spain.

\section{DNA extraction}

All isolates were grown on PDA for $7 \mathrm{e} 10 \mathrm{~d}$ at $25 \mathrm{C}$ and mycelium was then scraped from the surface of the growth medium and transferred to sterile tubes. DNA for amplification of specific gene or genomic regions was extracted using either a DNeasy Plant Mini Kit (Qiagen, California, USA) or a Nucleo-Spin ${ }^{\circledR}$ Plant kit (Macherey-Nagel, Duren, Germany). For the AFLP analyses, DNA was prepared by homogenising the mycelium harvested from a single plate in $500 \mathrm{~mL}$ TESProtK buffer [100mM Tris-HCL ( $\mathrm{pH} 8$ ); 10mM EDTA (ethylene diamine tetraacetate, $\mathrm{pH} 8.0$ ), $2 \%$ (w/v) SDS (Sodium dodecyl sulphate); $0.2 \mathrm{mg} / \mathrm{mL}$ Proteinase K (Roche, Indiana, USA)], followed by freezing the extraction mixtures at $-20 \mathrm{C}$ and then incubating them at $60 \mathrm{C}$ for $60 \mathrm{~min}$. To each of these, $320 \mathrm{~mL}$ CTAB-NaCl buffer $[2.5 \%(\mathrm{w} / \mathrm{v})$ CTAB (N-cetyl-N,N,N-trimethyl-ammonium bromide), $3.75 \mathrm{M} \mathrm{NaCl}$ ] was added, followed by incubation at $65 \mathrm{C}$ for $10 \mathrm{~min}$ and standard phenolchloroform (1:1) extractions (Sambrook et al. 1989) for DNA purification. The DNA was then precipitated with 0.6 volume of 2-propanol and overnight incubation at $-20 \mathrm{C}$, and harvested by centrifugation at $15700 \mathrm{~g}$ for $30 \mathrm{~min}$ at $4 \mathrm{C}$, washed with $70 \%$ ethanol, air-dried, and resuspended in deionised water.

\section{Fusarium circinatum identification}

Isolates were provisionally identified as Fusarium circinatum based on morphology, followed by subsequent confirmations based on molecular criteria. For identifications based on morphology, cultures were incubated on PDA, carnation leaf agar (Fisher et al. 1982) and synthetic low nutrient agar (Nirenberg 1976) for $10 \mathrm{~d}$ at $25 \mathrm{C}$ under near-ultraviolet light. Isolates were then examined 
microscopically to evaluate diagnostic characters reported by Nirenberg \& O'Donnell (1998). To determine the identity of cultures using DNA-based methods, isolates were subjected to the histone H3 PCR-RFLP (restriction fragment length polymorphism) diagnostic technique for $F$. circinatum using the primers, PCR conditions and digestion protocol described previously (Steenkamp et al. 1999). Isolates that produced the expected 232 and 250 base pair (bp) fragments that appeared as a doublet on $2 \%$ agarose gels after electrophoresis were considered as F. circinatum. A portion of the gene encoding translation elongation factor 1-alpha (EF-1a) was also sequenced, in both the forward and reverse directions, for seven isolates as described previously (Geiser et al. 2004) using primers EF1 and EF2 (O'Donnell et al. 1998), the ABI PRISM BigDye Terminator v3.0 Cycle Sequencing Kit (Applied Biosystems, California, USA) and a 3730 DNA Analyser (Applied Biosystems). Sequences generated were compared to those in the Fusarium identification database (Geiser et al. 2004) (http://fusarium.cbio.psu.edu/) using the BLAST search tool (Altschul et al. 1990).

\section{Vegetative compatibility groups (VCGs) and mating type}

VCGs were determined for a selection of isolates based on the protocol described by Correll et al. (1987). Isolates from both collections (Collections 1 and 2) were plated onto PDA with chlorate to obtain nitrate non-utilising (nit) mutants. The resulting nit mutants were subcultured and assigned to phenotypes (nit1, nit3 or NitM) (Correll et al. 1987) based on their ability to manifest wild type growth on minimal medium supplemented with different nitrogen sources (nitrate, nitrite or hypoxanthine, respectively). Pairings between nit mutants derived from different isolates and control pairings (different nit mutants from the same isolate) were performed on minimal medium with nitrate. Isolates were assigned to the same VCG when wild type growth developed along the line of contact between the isolate pairs being tested.

Mating type was assayed by amplifying MAT-1 and MAT-2-specific fragments using primer pairs GFmat1a and GFmat1b, and GFmat2c and GFmat2d, respectively (Steenkamp et al. 2000). The MAT-2-specific PCR product was sequenced from two isolates (representing different VCGs) to confirm that the amplified fragments represented the MAT-2 region of the MAT-locus.

\section{DNA-based polymorphic marker analyses}

Two sets of polymorphic DNA-markers were used to analyse the Fusarium circinatum isolates in this study. The first set included FC5 and FC9 (amplified with primers HB18p HB19 and HB34p HB35, respectively) developed by Britz et al. (2002b), and the second included G18, G60, G98 and G220 (amplified with primers $18 \mathrm{Fp} 18 \mathrm{R}, 60 \mathrm{Fp} 60 \mathrm{R}, 98 \mathrm{Fp} 98 \mathrm{R}$, and $220 \mathrm{Fp} 220 \mathrm{R}$, respectively) developed by Wikler \& Gordon (2000). The markers G18, G60, G98 and G220 were scored based on the size of amplicons, which were visualised using $1 \%(\mathrm{w} / \mathrm{v})$ agarose gel electrophoresis (Wikler \& Gordon 2000). For the two markers developed by Britz et al. (2002b), one primer from each set was labelled with a phosphoramidite fluorescent dye (MWG). For FC5, primer HB18 was labelled with PET and for primer set FC9, HB34 was labelled with FAM. The resulting FAM- and PET-labelled PCR products for each isolate were pooled and mixed with the GeneScan ${ }^{\mathrm{TM}}-500$ LIZ $^{\mathrm{TM}}$ size standard (Applied Biosystems) and loading buffer, after which samples were denatured at $95 \mathrm{C}$ for $15 \mathrm{~min}$ and run on an ABI Prism 377 DNA sequencer (Applied Biosystems). PCR product size was determined using GeneScan ${ }^{\circledR} 2.1$ analysis software (Applied Biosystems) and GeneMapper $^{\circledR} 3.0$ (Applied Biosystems).

Negative controls and positive controls were used in all PCR amplifications. The positive controls used were F. circinatum isolates 2494, 2481 and 2248 from the FABI Fusarium culture collection. These isolates had been used in either Britz van Heerden (2002) or Wikler \& Gordon (2000). PCR amplifications were repeated at least twice for any isolates for which no amplicon was obtained to 
confirm the absence of a product.

\section{AFLP analysis}

For AFLP analysis, the procedure described by Vos et al. (1995) was utilised, where genomic DNA was digested with restriction enzymes EcoRI (Roche) and MseI (New England Biolabs, Massachusetts, USA) and ligated to corresponding enzyme-specific oligonucleotide adapters. However, preselective and selective amplifications utilised zero-base-addition EcoRI and MseI adapter-specific primers and two-base-addition EcoRI and MseI adapter-specific primers, following the reaction and cycling conditions described previously (De Vos et al. 2008). A set of four twobase-addition EcoRI and MseI adopter-specific selective primers (EcoRI-AC + MseI-TT, EcoRI-TT $+M s e \mathrm{I}-\mathrm{TT}, E c o \mathrm{RIAC}+M s e \mathrm{I}-\mathrm{AT}$, and EcoRI-AT + MseI-AT) were used. In each case, the EcoR 1 selective primer was labelled with either an IRDye ${ }^{\mathrm{TM}} 700$ or IRDye ${ }^{\mathrm{TM}} 800$ infrared dye (LI-COR\#, Nebraska, USA). The resulting AFLP fragments and 50e700 bp size standard (LI-COR\#) were separated using the 4200 LI-COR ${ }^{\circledR}$ automated DNA sequencer and analysed with QUANTAR Version 1.0 (KeyGene Products B.V., Wageningen, The Netherlands) as described previously (Myburg et al. 2001). Only clear and well-resolved bands were scored manually as present or absent (faint or very intense bands were not considered). To ensure that the AFLP patterns observed in this study were reproducible, the AFLP procedure was repeated using DNA from new extractions.

\section{Genetic diversity and population structure}

Genetic diversity was assessed using a combination of data obtained from VCGs, mating type, AFLP analysis and the polymorphic DNA-markers. The allele frequency at each locus and average genetic diversity $(H)$ for loci derived from the polymorphic DNA-markers and AFLPs were determined using GenAlEx 6 (Peakall \& Smouse 2005).

\section{Results}

\section{Collection and identification of Fusarium circinatum}

Fusarium circinatum was isolated from 35 Pinus radiata trees displaying pitch canker-like symptoms sampled from across the Basque Country of Spain (Collection 1). The pitch canker fungus was also isolated from all trees sampled from three $P$. radiata plantations in the provinces Bizkaia and Gipuzkoa in the Basque Country (Collection 2). Ninety isolates were collected from the three $P$. radiata plantations and 16 isolates were collected from three insect species, Pissodes costaneus, Pityophthorus pulsceus and Tomicus piniperda, associated with plantation P3.

The isolates collected had coiled, sterile hyphae in the aerial mycelium, lunate macroconidia, polyphialides, and no chlamydospores. They also displayed typical F. circinatum H3 PCR-RFLP fingerprints. Comparison of EF-1a sequences for seven of the isolates with those in the Fusarium identification database also confirmed the identity of these isolates as $F$. circinatum, as the sequences for all seven were the same as that for isolate NRRL 25331 in the database (Geiser et al. 2004). The only exception was one isolate (CMW28967) that differed at one nucleotide position from NRRL 25331.

Ninety-six isolates were selected from the 141 isolates of $F$. circinatum collected in this study for further genetic analyses, as described below. This included all 35 isolates from Collection 1 and 61 isolates from Collection 2. The latter included all 30 isolates from plantation P3, 13 isolates each from plantations $\mathrm{P} 1$ and $\mathrm{P} 2$, and five isolates from insects collected in plantation P3. 


\section{Vegetative compatibility groups (VCG) and mating type}

VCGs were determined for a selection of 58 Basque Country Fusarium circinatum isolates from both collections. Two VCGs, designated A and B, were identified among these isolates. Of the 32 isolates tested from Collection 1, 14 were associated with VCG A and 18 with VCG B. Both VCGs were geographically distributed across the collection range (Fig 1C). All 26 isolates tested from Collection 2 (P1e3) belonged to VCG B.

PCR-based identification of mating type revealed that all 96 isolates of $F$. circinatum carry the MAT-2 idiomorph. The typical $800 \mathrm{bp}$ fragment was amplified from all the isolates tested. Analyses of the sequences of the selected MAT-2 PCR products (GenBank accession numbers GU369704 and GU369705) also showed that these fragments encoded the expected portion of the conserved HMG (high-mobility-group) domain of the MAT-2 idiomorph of F. circinatum (Steenkamp et al. 2000).

\section{Analyses using the polymorphic DNA-markers and AFLPs}

Application of the two sets of polymorphic DNA markers to the selected isolates of Fusarium circinatum revealed few polymorphisms. The primer set for FC9 amplified a $244 \mathrm{bp}$ fragment for all but one isolate, which amplified a $241 \mathrm{bp}$ fragment (Table 1). Primer set for FC5 amplified a $450 \mathrm{bp}$ fragment from all isolates tested (Table 1). The primer set for markers G18, G60, G98 and G220 amplified 510, 800, 950 and 400 bp fragments, respectively. Fragments corresponding to the expected size were produced in all the positive controls. However, for many of the isolates, the $G$ markers did not amplify any product, despite at least two additional attempts during which more diluted and/or concentrated DNA were used as template (Table 1). This was probably due to the lack of suitable primer binding sites in these isolates to allow proper amplification.

Using AFLPs, we identified 103 loci represented by fragments ranging between 50 and $500 \mathrm{bp}$ in size. Of the four selective primer sets used, EcoRI-AC + MseI-AT revealed nine polymorphisms, while EcoRI-AT + MseI-AT, EcoRI-AC + MseITT and EcoRI-TT + MseI-TT revealed four, three and one polymorphism, respectively. However, all 17 of these polymorphisms were associated with only three isolates. The remaining 93 isolates had identical profiles for all four AFLP primer sets used. As expected (Myburg et al. 2001), identical profiles were generated when the AFLP procedure was repeated on the selected isolates.

\section{Genetic diversity and population structure}

The genetic diversity for the Basque Fusarium circinatum population using both sets of polymorphic DNA-markers (FC5, FC9, G18, G60, G98 and G220) was $\mathrm{H}=0.169$, and $\mathrm{H}=0.248$ when analysing the four DNA-markers (G18, G60, G98 and G220) (Table 1). In these analyses, the absence of a PCR product was interpreted as a null allele at the specific locus. As the possibility that each of these nulls actually represent distinct alleles could not be ruled out, we also subjected the isolates to AFLP analysis, which confirmed the overall low diversity observed with the G and FC markers. For the 17 polymorphic AFLP loci, the genetic diversity was $\mathrm{H}=0.010$.

Within the population, nine genotypes (M1-9) were distinguished using the five polymorphic DNAmarkers (i.e., FC9 and G18, G60, G98 and G220) (Table 2, Fig 1A). Three genotypes (A1-3) were distinguished among the isolates using AFLPs (Table 2, Fig 1B). The most abundant genotypes, M1, M2 and A1, were associated with both VCG A and VCG B. The less frequently identified genotypes based on the polymorphic DNA markers (M3-6 and M8-9) and the AFLP genotypes (A23 ) were associated with VCG B only (Table 2). The VCG of the isolate with genotype M7 is unknown. All 10 isolates obtained from the single P3 tree and all isolates obtained from insects (Collection 2) were associated with the most common genotypes M1 (polymorphic DNA-markers) 
and A1 (ALFPs). Only one isolate, which represented genotypes M9 and A3, was distinguishable using both the AFLP and polymorphic DNA markers.

Table 1. Genetic diversity of Fusarium circinatum isolates based on polymorphic DNA-markers.

\begin{tabular}{|c|c|c|c|}
\hline Locus & Allele $^{a}$ & Frequency & $\begin{array}{l}\text { Genetic } \\
\text { diversity } \\
(H)^{c}\end{array}$ \\
\hline FC5 & 450 & 1 & - \\
\hline FC9 & 241 & 0.011 & - \\
\hline FC9 & 244 & 0.989 & - \\
\hline G18 & 510 & 0.738 & - \\
\hline G18 & Null & 0.262 & - \\
\hline G60 & 800 & 0.841 & - \\
\hline G60 & Null & 0.159 & - \\
\hline G98 & 950 & 0.852 & - \\
\hline G98 & Null & 0.148 & - \\
\hline $\mathrm{G} 220$ & 400 & 0.955 & - \\
\hline $\mathrm{G} 220$ & Null & 0.045 & - \\
\hline FC5, FC9 & - & - & $0.011( \pm 0.011)$ \\
\hline $\mathrm{G} 18, \mathrm{G} 60, \mathrm{G} 98, \mathrm{G} 220$ & - & - & $0.248( \pm 0.062)$ \\
\hline \multicolumn{4}{|l|}{$\mathrm{G} 60, \mathrm{G} 98, \mathrm{G} 220$} \\
\hline \multicolumn{4}{|c|}{$\begin{array}{l}\text { a Alleles are characterised in terms of the size (indicated in base } \\
\text { pairs) of the amplicons generated by the respective primer sets } \\
\text { for the various markers or null in the absence of a PCR product. } \\
\text { b Frequency = number of isolates with genotype/total number of } \\
\text { isolates (96). } \\
\text { c Average genetic diversity ( } \pm \text { Standard Error) over all loci consid- } \\
\text { ered; see Materials and methods. }\end{array}$} \\
\hline
\end{tabular}




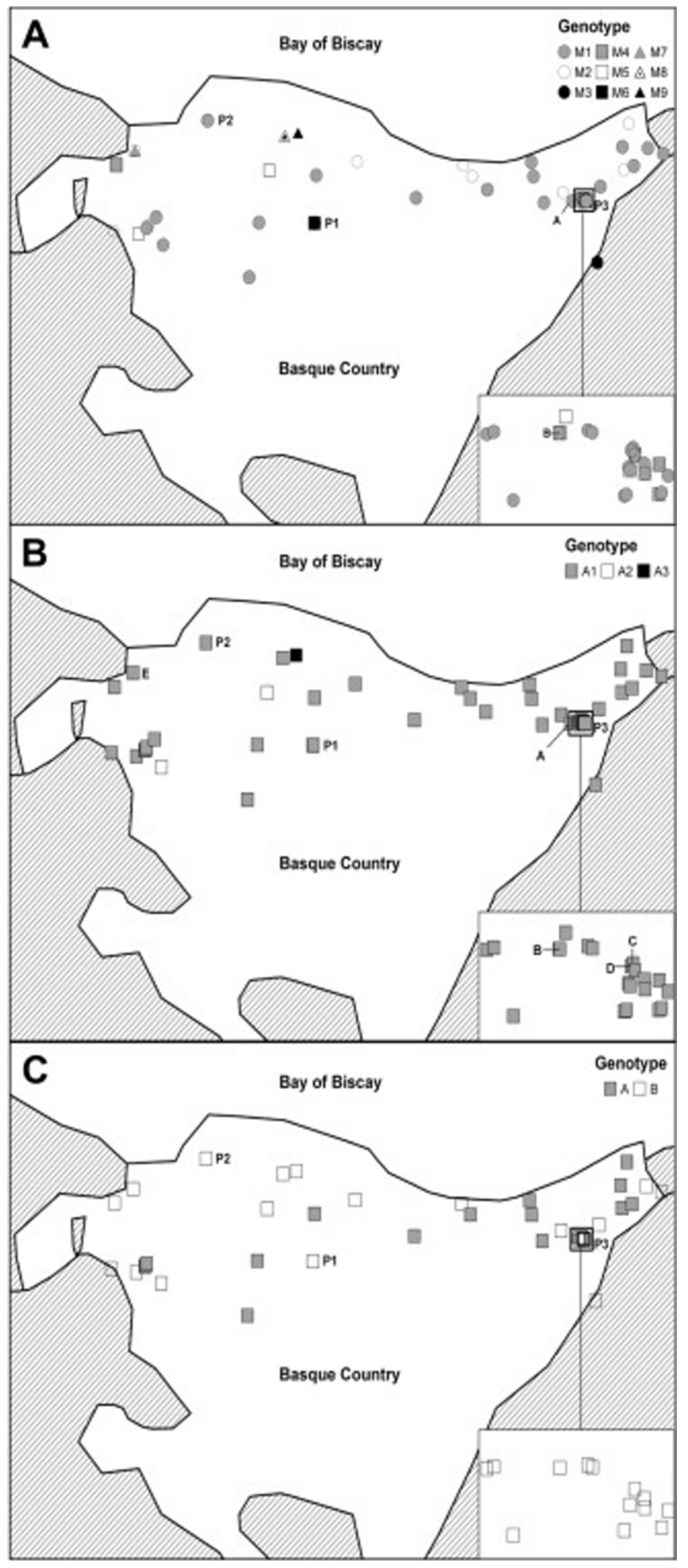


Figure 1. Genetic diversity and distribution of genotypes of Fusarium circinatum in the Basque Country, Spain. P1, P2 and P3 denote the location of the three Pinus radiata plantations sampled. Adjacent autonomous communities or countries (France) are thatched. (A) Nine genotypes (M1-9) obtained using six loci from the polymorphic DNA-markers sets (FC5, FC9, G18, G60, G98 \& G220). P1 represents nine M1, one M2, one M3 and one M6 genotypes. P2 represents nine M1 and three M5 genotypes. A represents four M1 and B represents 10 M1 and one M4 genotypes. (B) Three genotypes (A1-3) obtained using 103 loci from AFLP analysis. P1 and P2 each represent 13 A1 genotypes. A represents four A1 genotypes, B represents 11 A1 genotypes, and C, D and E each represent two A1 genotypes. (C) Two vegetative compatibility groups (A and B). P1 represents four $\mathrm{B}$ genotypes and $\mathrm{P} 2$ represents $11 \mathrm{~B}$ genotypes.

Table 2. Genotype distribution of Fusarium circinatum isolates based on VCG, polymorphic DNAmarker and AFLP analyses.

$$
\text { Genotype Frequency }{ }^{\mathrm{a}} \quad \mathrm{VCG}^{\mathrm{b}} \quad \text { Collection Polymorphism }{ }^{\mathrm{c}} \text { [Locus }
$$

\begin{tabular}{|c|c|c|c|c|c|}
\hline & 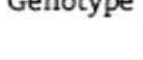 & 年 & & 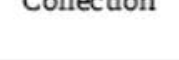 & (Allele) or AFLP set: Allele $(1 / 0)]$ \\
\hline Polymorphic & M1 & 0.68 & A, B & 1,2 & FC9 (244), G18 (510), G60 (800), G98 (950), G220 (400) \\
\hline \multirow[t]{8}{*}{ DNA-marker } & M2 & 0.12 & $A, B$ & 1,2 & FC9 (244), G18 (null), C60 (800), G98 (950), G220 (400) \\
\hline & M3 & 0.09 & B & 1,2 & FC9 (244), G18 (510), G60 (null), G98 (950), G220 (null) \\
\hline & M4 & 0.04 & B & 1,2 & FC9 (244), G18 (510), C60 (800), G98 (null), G220 (400) \\
\hline & MS & 0.02 & B & 1,2 & FC9 (244), G18 (510), C60 (null), G98 (950), G220 (400) \\
\hline & M6 & 0.02 & B & 1 & FC9 (244), G18 (null), C60 (800), G98 (null), G220 (400) \\
\hline & M7 & 0.01 & Unknown & 1 & FC9 (244), G18 (null), C60 (null), G98 (null), G220 (400) \\
\hline & M8 & 0.01 & B & 2 & FC9 (244), G18 (null), C60 (null), G98 (null), G220 (null) \\
\hline & Mgd & 0.01 & B & 1 & FC9 (241), G18 (null), C60 (null), G98 (null), G220 (null) \\
\hline Total & 9 & 1 & $n / a$ & $n / a$ & $n / a$ \\
\hline \multirow[t]{3}{*}{ AFLP } & A1 & 0.97 & A, B & 1,2 & $\begin{array}{l}\text { EcoRl-AC +Msel-AT: } 215(0), 204(0), 157(0), 150(0), 145(0), \\
\text { 143(0), 108(0), 107(0); } \\
\text { EcoRl-AT + Msel-AT: } 145(1), 102(1), 90(1), 65(0) ; \\
\text { EcoRl-AC+Msel-TT: } 185(0), 140(0), 80(1) ; \\
\text { EcoRl-TT + Msel-TT: } 128(0)\end{array}$ \\
\hline & A2 & 0.02 & B & 1 & $\begin{array}{l}\text { EcoRl-AC+Msel-AT: } 215(1), 204(0), 157(1), 150(0), 145(1), \\
\text { 143(0), 108(1), 107(1); } \\
\text { EcoRI-AT + Msel-AT: } 145(1), 102(1), 90(1), 65(1) ; \\
\text { EcoRI-AC+Msel-TT: } 185(1), 140(1), 80(1) ; \\
\text { EcoRL-TT + Msel-TT: } 128(0)\end{array}$ \\
\hline & $\mathrm{A} 3^{\mathrm{d}}$ & 0.01 & B & 1 & $\begin{array}{l}\text { EcoRI-AC +Msel-AT: } 215(0), 204(1), 157(0), 150(1), 145(0), \\
\text { 143(0), 108(0), 107(O); } \\
\text { EcoRl-AT +Msel-AT: } 145(0), 102(0), 90(0), 65(0) ; \\
\text { EcoRl-AC+Msel-TT: } 185(0), 140(0), 80(0) ; \\
\text { EcoRl-TT + Msel-TT: } 128(0)\end{array}$ \\
\hline Total & 3 & 1 & $n / a$ & $n / a$ & $n / a$ \\
\hline
\end{tabular}

a Frequency = number of isolates with genotype/total number of isolates (96).

b VCGs associated with each genotype.

c Polymorphic alleles are characterised in terms of the size (indicated in base pairs) of the amplicons generated by the respective primer sets for the various markers. Presence or absence of these fragments or alleles is indicated by (1) and $(0)$, respectively.

d Genotypes common to both molecular analyses methods.

\section{Discussion}

The results of this study show the population of Fusarium circinatum in the Basque Country of Spain to be relatively homogeneous. Only two VCGs were identified among the isolates studied and both were associated with the same mating type. AFLPs and the FC markers (Britz et al. 2002b) also showed low levels of genetic diversity. Although the G marker set (Wikler \& Gordon 2000) revealed somewhat more diversity, the extent of polymorphism in the Basque Country population was limited relative to that observed in a global sampling of $F$. circinatum populations (Wikler \& Gordon 2000). In prior studies, both FC (Britz et al. 2002b) and G (Wikler \& Gordon 2000) marker sets detected multiple alleles at each of the loci assayed, as compared to only one or two alleles per locus in the present study. 
The most common genotype based on the FC and $\mathrm{G}$ marker sets (68 \% of the sample) was associated with both VCGs, whereas the remaining genotypes were associated only with VCG B. Likewise the most common genotype based on AFLPs (97\%) was associated with VCGs A and B, and the remaining genotypes only with VCG B. This pattern would be consistent with a clonal relationship between isolates associated with different VCGs. In this hypothetical relationship VCG $\mathrm{B}$ would be the progenitor, with VCG A having been derived from VCG B through a mutation affecting somatic compatibility. Similar relationships have been described in the Florida and California populations of $F$. circinatum (Wikler \& Gordon 2000) and experimental evidence suggests that 'novel' VCGs may originate spontaneously in the absence of outcrossing (Petersen \& Gordon 2005).

Whether or not VCGs A and B share a clonal relationship, VCG diversity in the Basque Country population is clearly low, which is consistent with the recent establishment of this population through one or a limited number of introductions. Likewise identification of only five VCGs in the California population of $F$. circinatum, as compared to 45 VCGs in a well established Florida population, was taken as evidence in support of recent introduction of $F$. circinatum to California (Correll et al. 1992). It is not known if the pitch canker infestations in the Basque Country and in the nearby autonomous communities of Galicia, Asturias and Cantabria (Perez-Sierra et al. 2007) have separate origins, or resulted from dispersal following an introduction into one region. Insight into this question might be gained through a broader geographic assessment of diversity and relationships among $F$. circinatum populations in Spain, based on VCGs and/or informative molecular markers.

Fusarium circinatum isolates from the Basque Country were found to be associated exclusively with the MAT-2 mating type. However, both mating types have been reported to occur in other parts of Northern Spain (Perez-Sierra et al. 2007), suggesting that sexual reproduction could occur in this region. Although studies in California have shown that co-occurrence of two mating types does not preclude maintenance of a clonal population structure (Gordon et al. 1996, 2006b), the risk of sexual reproduction in Spain remains a concern. The possibility of selection for greater virulence to pine is suggested by the significant variation in virulence among $F$. circinatum isolates reported by Perez-Sierra et al. (2007). It was noted in this same study that MAT-1 isolates were more virulent than isolates associated with the MAT-2 idiomorph (Perez-Sierra et al. 2007), whereas Gordon et al. $(1998 b, 2006 a)$ found the reverse to be true. This discrepancy indicates there is not a consistent association between mating type and virulence. Perez-Sierra et al. (2007) also reported that MAT-2 isolates lacked coiled, sterile hyphae, whereas MAT-2 isolates from the Basque Country all produced coiled, sterile hyphae characteristic of $F$. circinatum.

Fusarium circinatum has been associated with numerous insect species throughout its range. In California, engraver beetles (Fox et al. 1991) and twig beetles (Storer et al. 2004) are thought to play critical roles as vectors and wounding agents, whereas insects are accorded much less importance in the pitch canker disease cycle in the southeastern United States (Blakeslee \& Oak 1979). Several bark beetle and weevil species are associated with F. circinatum in the Basque region of Spain (Romon et al. 2007). In this study, there was no difference in genetic diversity of $F$. circinatum isolates associated with insects versus other isolates from Collections 1 and 2 . The association of F. circinatum with insects makes eradication of this pathogen in Spain difficult, as it can provide a method for dissemination beyond a zone of infestation. Eradication of the pathogen from Spain is also problematic because of its present distribution (Perez-Sierra et al. 2007) and the predicted climatic suitability for disease establishment in this region (Ganley et al. 2009). 


\section{Acknowledgements}

The authors would like to thank Lucy Manning for preparation of the maps. We are grateful to the Agriculture, Fish and Food Department of the Basque Government, and the Education, Universities and Research Department of the Basque Government (Spain); the Forest Biosecurity Research Council, National Centre for Advanced Bio-Protection Technologies, and the Foundation for Research Science \& Technology (New Zealand); members of Tree Protection Co-operative Programme, the National Research Foundation and the THRIP initiative of the Department of Trade and Industry (South Africa) for financial support to conduct this study.

\section{References}

Aegerter BJ, Gordon TR, 2006. Rates of pitch canker induced seedling mortality among Pinus radiata families varying in levels of genetic resistance to Gibberella circinata (anamorph Fusarium circinatum). Forest Ecology and Management 235: 14-17.

Altschul SF, Gish W, Miller W, Myers EW, Lipman DJ, 1990.Basic local alignment search tool. Journal of Molecular Biology 215: 403-410.

Blakeslee GM, Oak SW, 1979. Significant mortality associated with pitch canker infection of slash pine in Florida. Plant Disease Reporter 63: 1023-1025.

Braganca H, Diogo E, Moniz F, Amaro P, 2009. First report of pitch canker on pines caused by Fusarium circinatum in Portugal. Plant Disease 93: 1079.

Britz van Heerden H, 2002. Taxonomy and population genetics of Fusarium subglutinans sensu lato on pine and mango. Doctoral thesis, University of Pretoria.

Britz H, Coutinho TA, Gordon TR, Wingfield MJ, 2001. Characterisation of the pitch canker fungus, Fusarium circinatum, from Mexico. South African Journal of Botany 67: 609-614.

Britz H, Coutinho TA, Wingfield BD, Marasas WFO, Wingfield MJ, 2005. Diversity and differentiation in two populations of Gibberella circinatum in South Africa. Plant Pathology 54: 4652.

Britz H, Coutinho TA, Wingfield MJ, Marasas WFO, 2002a. Validation of the description of Gibberella circinatum and morphological differentiation of the anamorph Fusarium circinatum. Sydowia 54: 9-22.

Britz H, Wingfield BD, Coutinho TA, Wingfield MJ, 2002b. Sequence characterized amplified polymorphic markers for the pitch canker pathogen, Fusarium circinatum. Molecular Ecology Notes 2: 577-580.

Carlucci A, Colatruglio L, Frisullo S, 2007. First report of pitch canker caused by Fusarium circinatum on Pinus halepensis and P. pinea in Apulia (southern Italy). Plant Disease 91: 1683.

Correll JC, Gordon TR, McCain AH, 1992. Genetic diversity in California and Florida populations of the pitch canker fungus Fusarium subglutinans f. sp. pini. Phytopathology 82: 415-420.

Correll JC, Klittich CJR, Leslie JF, 1987. Nitrate nonutilizing mutants of Fusarium oxysporum and their use in vegetative compatibility tests. Phytopathology 77: 1640-1646. 
De Vos L, Myburg AA, Wingfield MJ, Desjardins AE, Gordon TR, Wingfield BD, 2008. Complete genetic linkage maps from an interspecific cross between Fusarium circinatum and Fusarium subglutinans. Fungal Genetics and Biology 44: 701-714.

Dwinell LD, Barrows-Broaddus JB, Kuhlman EG, 1985. Pitch canker: a disease complex of southern pines. Plant Disease 69: 270-276.

Fisher NL, Burgess LW, Toussoun TA, Nelson PE, 1982. Carnation leaves as a substrate and for preserving cultures of Fusarium species. Phytopathology 72: 151-153.

Fox JW, Wood DL, Koehler CS, O’Keefe ST, 1991. Engraver beetles (Scolytidae: Ips species) as vectors of the pitch canker fungus, Fusarium subglutinans. Canadian Entomologist 123: 13551367.

Ganley RJ, Watt MS, Manning L, Iturritxa E, 2009. A global climatic risk assessment of pitch canker disease. Canadian Journal of Forest Research 39: 2246-2256.

Geiser DM, Jimenez-Gasco M, Kang S, Makalowska I, Veeraraghavan N, Ward TJ, Zhang N, Kuldau GA, O'Donnell K, 2004. FUSARIUM-ID v.1.0: a DNA sequence database for identifying Fusarium. European Journal of Plant Pathology 110: 473-479.

Gonzalez-Ariasa A, Martınez de Aranob I, Barcena-Ruızc MJ, Besgab G, Onaindia M, 2006. Origin of atmospheric deposition and canopy buffering capacity in stands of radiata pine and pedunculate oak in the Basque Country. Forest Ecology and Management 229: 268-284.

Gordon TR, 2006. Pitch canker disease of pines. Phytopathology 96: 657-659.

Gordon TR, Kirkpatrick SC, Aegerter BJ, Wood DL, Storer AJ, 2006a. Susceptibility of Douglas fir (Pseudotsuga menziesii) to pitch canker, caused by Gibberella circinata (anamorph $=$ Fusarium circinatum). Plant Pathology 55: 231-237.

Gordon TR, Kirkpatrick SC, Petersen JC, Friel CJ, 2006b. Potential diversity in vegetative compatibility groupings in the California population of Gibberella circinata. Mycological Research 110: $936-940$.

Gordon TR, Okamoto D, Storer AJ, Wood DL, 1998a. Susceptibility of five landscape pines to pitch canker disease, caused by Fusarium subglutinans f. sp. pini. HortScience 33: 868-871.

Gordon TR, Storer AJ, Okamoto D, 1996. Population structure of the pitch canker pathogen, Fusarium subglutinans f. sp. pini, in California. Mycological Research 100: 850-854.

Gordon TR, Storer AJ, Wood DL, 2001. The pitch canker epidemic in California. Plant Disease 85: 1128-1139.

Gordon TR, Wikler KR, Clark SL, Okamoto D, Storer AJ, Bonello P, 1998b. Resistance to pitch canker disease, caused by Fusarium subglutinans f.sp. pini, in Monterey pine (Pinus radiata). Plant Pathology 47: 706-711.

Hepting GH, Roth ER, 1946. Pitch canker, a new disease of some southern pines. Journal of Forestry 44: 724-744. 
Hepting GH, Roth ER, 1953. Host relations and spread of the pine pitch canker disease. Phytopathology 43: 475.

Hodge GR, Dvorak WS, 2000. Differential responses of Central American and Mexican pine species and Pinus radiata to infection by the pitch canker fungus. New Forests 19: 241-258.

Kerenyi Z, Zeller K, Hornok L, Leslie JF, 1999. Molecular standardization of mating type terminology in the Gibberella fujikuroi species complex. Applied and Environmental Microbiology 65: 4071-4076.

Kobayashi T, Muramoto M, 1989. Pitch canker of Pinus luchuensis, a new disease in Japanese forests. Forest Pests 38: 169-173.

Landeras E, Garcia P, Fernandez Y, Brana M, Fernandez-Alonso O, Mendez-Lodos S, Perez-Sierra A, Leon M, Abad-Campos P, Berbegal M, Beltran R, Garcia-Jimenez J, Armengol J, 2005. Outbreak of pitch canker caused by Fusarium circinatum on Pinus spp. in Northern Spain. Plant Disease 89: 1015.

Lee JK, Lee S-H, Yang S-I, Lee Y-W, 2000. First report of pitch canker disease on Pinus rigida in Korea. Plant Pathology Journal 16: 52-54.

McCain AH, Koehler CS, Tjosvold SA, 1987. Pitch canker threatens California pines. California Agriculture 41: 22-23.

Myburg AA, Remington DL, O'Malley DM, Sederoff RR, Whetten RW, 2001. High-throughput AFLP analysis using infrared dye-labeled primers and an automated DNA sequencer. BioTechniques 30: 348-357.

Nirenberg HI, 1976. Untersuchungen uber die morphologische und biologische Differenzierung in der Fusarium-Sektion Liseola. Mitteilungen aus der Biologischen Bundesanstalt fur Land- und Forstwirtschaft Berlin-Dahlem 169: 1-117.

Nirenberg HI, O'Donnell K, 1998. New Fusarium species and combinations within the Gibberella fujikuroi species complex. Mycologia 90: 434-458.

O’Donnell K, Cigelnik E, Nirenberg HI, 1998. Molecular systematics and phylogeography of the Gibberella fujikuroi species complex. Mycologia 90: 465-493.

Peakall R, Smouse PE, 2005. GenAlEx 6: genetic analysis in Excel. Population genetic software for teaching and research. Molecular Ecology Notes 6: 288-295.

Petersen JC, Gordon TR, 2005. Spontaneous changes in vegetative compatibility in the ascomycete Gibberella circinata. Phytopathology 95: S83.

Perez-Sierra A, Landeras E, Leon M, Berbegal M, Garcia-Jimenez J, Armengol J, 2007. Characterization of Fusarium circinatum from Pinus spp. in northern Spain. Mycological Research 111: $832-839$.

Romon P, Iturrondobeitia JC, Gibson K, Lindgren BS, Goldarazena A, 2007. Quantitative association of bark beetles with pitch canker fungus and effects of verbenone on their semiochemical communication in monterey pine forests in Northern Spain. Environmental Entomology 36: 743-750. 
Sambrook J, Fritsch EF, Maniatis T, 1989. Molecular Cloning: a Laboratory Manual. Cold Spring Harbor Laboratory Press, New York.

Steenkamp ET, Wingfield BD, Coutinho TA, Wingfield MJ, Marasas WFO, 1999. Differentiation of Fusarium subglutinans f. sp. pini by histone gene sequence data. Applied and Environmental Microbiology 65: 3401-3406.

Steenkamp ET, Wingfield BD, Coutinho TA, Zeller KA, Wingfield MJ, Marasas WFO, Leslie JF, 2000. PCR-based identification of MAT-1 and MAT-2 in the Gibberella fujikuroi species complex. Applied and Environmental Microbiology 66: 4378-4382.

Storer AJ, Gordon TR, Clark SL, 1998. Association of the pitch canker fungus, Fusarium subglutinans f. sp. pini with Monterey pine seeds and seedlings in California. Plant Pathology 47: 649-656.

Storer AJ, Wood DL, Gordon TR, 2004. Twig beetles, Pityophthorus spp. (Coleoptera: Scolytidae), as vectors of the pitch canker pathogen in California. Canadian Entomologist 136: 685-693.

Storer AJ, Gordon TR, Wood DL, Bonello P, 1997. Pitch canker disease of pines: current and future impacts. Journal of Forestry 95: 21-26.

Viljoen A, Marasas WFO, Wingfield MJ, Viljoen CD, 1997a. Characterization of Fusarium subglutinans f. sp. pini causing root disease of Pinus patula seedlings in South Africa. Mycological Research 101: 437-445.

Viljoen A, Wingfield MJ, Gordon TR, Marasas WFO, 1997b. Genotypic diversity in a South African population of the pitch canker fungus Fusarium subglutinans f. sp. pini. Plant Pathology 46: $590-593$.

Viljoen A, Wingfield MJ, Marasas WFO, 1994. First report of Fusarium subglutinans f. sp. pini on seedlings in South Africa. Plant Disease 78: 309-312.

Vos P, Hogers R, Bleeker M, Reijans M, van de Lee T, Hornes M, Frijters A, Pot J, Paleman J, Kuiper M, 1995. AFLP: a new technique for DNA fingerprinting. Nucleic Acids Research 23: 44074414.

Wikler K, Gordon TR, 2000. An initial assessment of genetic relationships among populations of Fusarium circinatum in different parts of the world. Canadian Journal of Botany 78: 709-717.

Wingfield MJ, Hammerbacher A, Ganley RJ, Steenkamp ET, Gordon TR, Wingfield BD, Coutinho TA, 2008. Pitch canker caused by Fusarium circinatum: a growing threat to pine plantations and forests worldwide. Australasian Plant Pathology 37: 319-334.

Wingfield MJ, Jacobs A, Coutinho TA, Ahumada R, Wingfield BD, 2002. First report of the pitch canker fungus, Fusarium circinatum, on pines in Chile. Plant Pathology 51: 397. 